\title{
Clinical Reasoning: Moyamoya disease masquerading as acute refractory cerebral vasospasm
}

Alvin S. Das, MD, David P. Lerner, MD, Xenos L. Mason, MD, Mohammad A. Aziz-Sultan, MD, Henrikas Vaitkevicius, MD, Steven K. Feske, MD, and Saef Izzy, MD

Neurology ${ }^{\circledR}$ 2018;91:e594-e598. doi:10.1212/WNL.0000000000005952

\section{Correspondence}

Dr. Das

asdas@mgh.harvard.edu

\section{Section 1}

A 53-year-old Salvadoran woman with hyperlipidemia and no previous neurologic complaints presented to the emergency department with sudden-onset right-sided weakness and dysarthria while speaking with a friend. Two days prior to presentation, she endorsed a mild bifrontal headache but denied any constitutional symptoms.

On arrival, the patient's vital signs were normal. Initial neurologic examination demonstrated flaccid dysarthria, right-sided upper motor neuron facial droop, and quadriparesis. Basic laboratory evaluation and urine toxicology were unremarkable. CT scan of the head revealed a partially calcified sellar mass, and CT angiography (CTA) revealed multifocal irregular narrowing throughout the circle of Willis (figure 1A). Brain MRI demonstrated a central hemorrhagic component in the pituitary gland as well as an ischemic stroke in the left frontal lobe that extended to the posterior insula without areas of abnormal enhancement (figure 1, B and C).

\section{Question for consideration:}

1. What is your differential diagnosis?
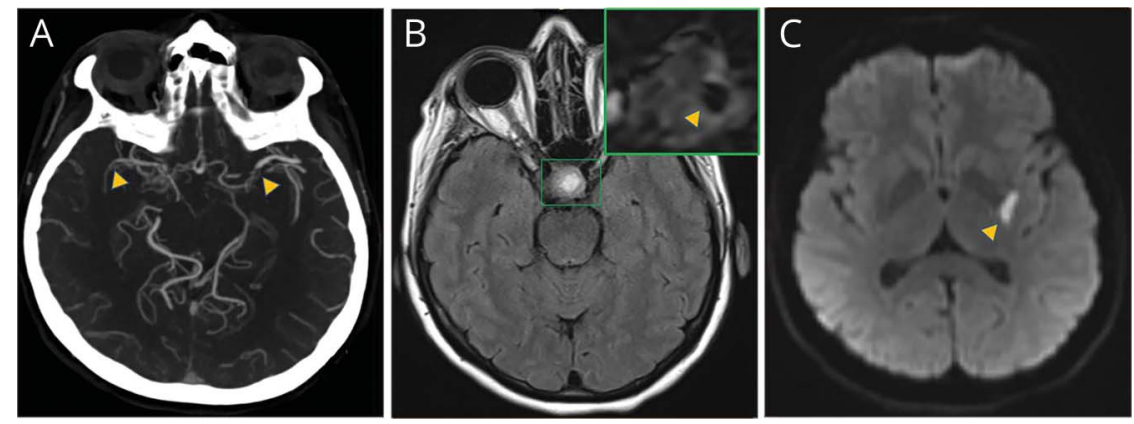

(A) CT angiography demonstrates multifocal vascular irregularities (arrowheads) raising the concern for vasospasm. (B) T2 fluid-attenuated inversion recovery shows a pituitary macroadenoma with hemorrhagic component on SWI (inset, arrowhead). (C) DWI sequence shows restricted diffusion in left frontal lobe extending to the posterior insula (arrowhead). 


\section{Section 2}

We have the presentation of a diffuse vasculopathy causing an ischemic stroke. Although there is no visible subarachnoid hemorrhage (SAH), in the context of the patient's headache and diffuse narrowing on CTA, vasospasm and reversible cerebral vasoconstriction syndrome (RCVS) remain high on the differential. In addition, pituitary hemorrhage (apoplexy) may have triggered a diffuse vasospastic process capable of producing a headache. ${ }^{1}$ Finally, in the context of diffuse vessel abnormalities, a primary or secondary CNS vasculitis should be considered. In reviewing the differential diagnosis for stroke in the young, one must always consider hypercoagulable state or dissection; however, neither is consistent with the history.

In the neurointensive care unit, the patient was started on aspirin and verapamil given the concern for RCVS.
Extensive hypercoagulable, rheumatologic, and infectious evaluations were all negative. A lumbar puncture (LP) revealed 8 total nucleated cells $/ \mu \mathrm{L}$ (reference range $0-3$ / $\mu \mathrm{L}$ ), 114 red blood cells $/ \mu \mathrm{L}$ (reference range $0 / \mu \mathrm{L}$ ), glucose of $60 \mathrm{mg} / \mathrm{dL}$ (reference range $40-70 \mathrm{mg} / \mathrm{dL}$ ), and protein of $38 \mathrm{mg} / \mathrm{dL}$ (reference range $10-44 \mathrm{mg} / \mathrm{dL}$ ). Because of the pituitary mass, endocrine workup was performed and revealed a normal thyroid-stimulating hormone, decreased free $\mathrm{T} 4$, elevated prolactin, normal follicle-stimulating hormone, and low luteinizing hormone.

\section{Questions for consideration:}

1. In the context of the LP results, how has your differential diagnosis changed?

2. What additional testing should be pursued? 


\section{Section 3}

While the diagnosis remains unclear, the patient's mild CSF pleocytosis raises concern for an inflammatory process such as primary angiitis of the CNS (PACNS). Commonly, PACNS does not present with constitutional symptoms. ${ }^{2}$ The MRI did not show any areas of gadolinium enhancement, a finding that is seen in over one-third of patients with CNS vasculitis. ${ }^{3}$ In addition to vasculitis, the pleocytosis could be a reactive phenomenon to stroke.

The constellation of endocrine values suggests that the patient has a nonsecreting pituitary adenoma with pituitary stalk compression resulting in prolactin elevation and gonadotropin, thyrotropin, and corticotropin deficiencies. Because her clinical state was tenuous, and her diagnosis was unclear, consensus decision was made to remove the mass in a delayed fashion as an outpatient. Given the concern for vasculitis as well as endocrine dysfunction, the patient was started on steroids.

The following afternoon, the patient experienced acute worsening of her aphasia. Similar to the treatment of SAHassociated vasospasm, ${ }^{4}$ the patient's blood pressure was augmented with vasopressor agents and calcium channel blockers. Transcranial Doppler (TCD) ultrasound did not show any evidence of vasospasm initially, but magnetic resonance angiography (MRA) demonstrated mild progression of the vasculopathy, and brain MRI showed infarcts in left hemispheric watershed territory. Magnetic resonance perfusion demonstrated increased cerebral blood volume in the left frontal lobe and decreased cerebral blood flow in the infarcted territory. Transthoracic echocardiogram revealed normal heart structure without any evidence of interatrial shunt.

Over the next few days, TCDs progressed to show elevated mean velocities of the left posterior cerebral artery, basilar artery, and right middle cerebral artery (MCA), raising the concern for vasospasm. The patient continued to experience fluctuations in her aphasia and right-sided strength, and a repeat CTA revealed worsening vasculopathy. Repeat LP showed resolution of the pleocytosis.

\section{Question for consideration:}

1. What other testing can be pursued to confirm the differential diagnosis? 


\section{Section 4}

Despite medical optimization of vasospasm treatment and concurrent steroid administration, the patient had radiographic and clinical disease progression. Although the CTA demonstrated large-vessel involvement, conventional angiography may be able to further delineate this process and provide information regarding the chronicity and nature of the vasculopathy. Angiography can show areas of narrowing and dilation that support the diagnosis of vasculitis and can complement a brain biopsy. As other guidelines suggest, whenever a large- or medium-vessel vasculitis is suspected, angiography should be pursued. ${ }^{5}$ Moreover, angiography may be used to treat vasospasm by infusion of intra-arterial calcium channel blockers. However, its benefit over IV therapies has not been established, so its use should be limited to medically refractory cases and must be weighed against its procedural risks.

Vasospasm due to pituitary hemorrhage would cause a monophasic presentation, rather than an ongoing fulminant syndrome, ${ }^{1}$ which raises the concern for vasculitis. If a systemic illness is suspected, PET of the entire body can be pursued to look for evidence of a systemic vasculitis. In PACNS, repeat CSF evaluations are rarely normal, ${ }^{6}$ although CSF studies in vasculitis can be normal initially. If the vasculitis is not managed aggressively, ongoing symptoms can occur in refractory cases, warranting further immunosuppression. However, escalation of immunosuppression should not be performed without attempting to obtain a tissue diagnosis. $^{6}$ The adverse effects of biopsy are much less than that of toxicity from aggressive immunosuppression, ${ }^{5}$ and biopsy is the gold standard for the diagnosis of vasculitis. ${ }^{6}$

Given the lack of a definitive diagnosis, the decision was made to pursue conventional angiography. In addition to recapitulating several findings on CTA, angiography revealed extensive collateral networks with lenticulostriate branches exhibiting a hazy appearance similar to a puff of smoke (figure 2, A-C). Overall, these findings were consistent with bilateral Suzuki stage III moyamoya disease (MMD) affecting the left hemisphere more than the right hemisphere.
Once this diagnosis was made, verapamil was discontinued. Hemoglobin electrophoresis was performed to exonerate secondary causes of moyamoya angiopathy, but showed no abnormal hemoglobin chains. In an emergent fashion, the patient underwent a left superficial temporal artery (STA)MCA bypass surgery. Postoperative CTA showed slight improvement in the vasculopathy. At the time of her discharge, the patient was able to name $1 / 3$ of objects and had a mild pronator drift of the right arm. Several months after discharge, the patient received a right STA-MCA bypass surgery as well as a transsphenoidal surgery to resect the pituitary macroadenoma. With the exception of minor headaches, she experienced no further symptomatic progression over the next year, and her aphasia had improved.

\section{Discussion}

Moyamoya angiopathy is composed of MMD and moyamoya syndrome. MMD is an idiopathic intracranial vasculopathy that results in progressive stenosis of the bilateral internal carotid arteries (ICAs) with subsequent development of an extensive collateral network. Moyamoya syndrome is characterized by unilateral or bilateral moyamoya angiopathy associated with a host of processes such as meningitis, neurofibromatosis, sickle cell disease, or prior skull base radiation. The diagnosis of MMD can be challenging given the spectrum of overlap between various other arteriopathies. Herein, the diagnosis remained obscure for several days and led to a delay in definitive surgical treatment. It is helpful to review these conditions given their frequent misdiagnosis and lack of recognition.

The initial presentation of headache and vasculopathy led to the differential diagnosis of PACNS, RCVS, and MMD. In differentiating RCVS from vasculitis, there are certain features including recurrent thunderclap headache, noninflammatory CSF, presence of cortical subarachnoid hemorrhage, and sausage string appearance on angiography that make the diagnosis of RCVS more likely (table). ${ }^{7}$ However, without advanced and often invasive testing, MMD and PACNS are difficult to distinguish. Although CSF studies are usually able

Figure 2 Conventional angiography of left and right internal carotid arteries (ICAs)
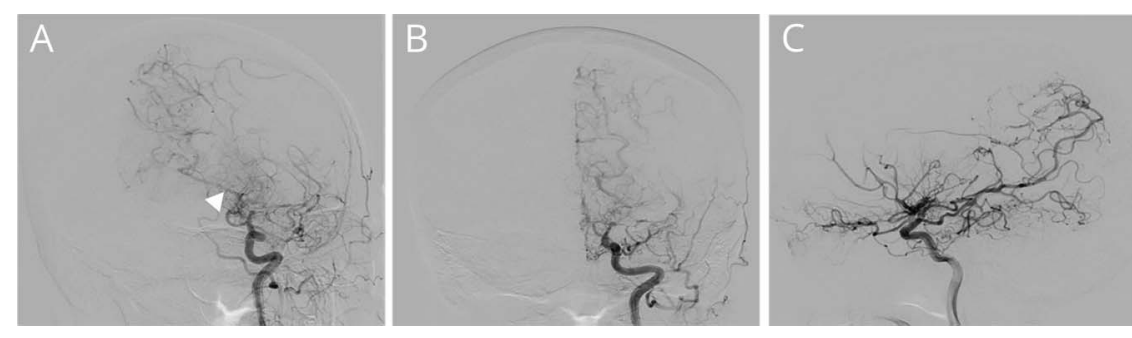

(A) Reverse oblique and (B) standard left ICA injections demonstrate brisk external carotid artery filling with several areas of stenosis at the level at the ICA bifurcation, anterior cerebral artery (ACA), and middle cerebral artery (MCA). Ophthalmic artery is of large caliber and lenticulostriate vessels appear hazy, giving the appearance of a puff of smoke (arrowhead). (C) R ICA injection demonstrates areas of stenosis involving the carotid terminus and the MCA/ACA bifurcation. There is a large caliber ophthalmic artery with prominent lenticulostriate vessels with a hazy appearance. The constellation of these images suggests Suzuki stage III moyamoya disease affecting the left cerebral hemisphere more than the right. 
Table Characteristics of reversible cerebral vasoconstriction syndrome (RCVS), primary angiitis of the CNS (PACNS), and moyamoya disease $(\mathrm{MMD})^{7,8}$

\begin{tabular}{llll}
\hline & RCVS & PACNS & MMD \\
\hline Mean age at onset, $\mathbf{y}$ & 42.0 & 42.5 & 31.0 \\
\hline Female predominance & $2.6: 1$ & $1.6: 1$ & $4.25: 1$ \\
\hline CSF findings & Normal & Pleocytosis and elevated protein & Normal \\
\hline Angiography sensitivity, $\%$ & 100 & 76.5 & 100 \\
\hline Angiography findings & Sausage-string appearance & $\begin{array}{l}\text { Areas of thinning and dilation with } \\
\text { areas of significant stenosis }\end{array}$ & $\begin{array}{l}\text { Occlusion of the distal ICAs } \\
\text { with extensive collaterals }\end{array}$ \\
\hline MRI findings & Usually normal, occasional SAH/IS & IS of varying ages & ICH (adults) or IS (children) \\
\hline Gadolinium enhancement & No & Yes & No \\
\hline TCD abnormalities, $\%$ & 69 & 47 & $82-100$ \\
\hline Headache quality & Thunderclap & Dull, insidious & Migrainous \\
\hline Clinical course & Benign & Slowly progressive & Variable \\
\hline Differential diagnosis & $\begin{array}{l}\text { Pituitary apoplexy, FMD, } \\
\text { intracranial atherosclerosis, } \\
\text { SAH, dissection, PACNS, MMD }\end{array}$ & $\begin{array}{l}\text { CADASIL, systemic vasculitides } \\
\text { due to rheumatologic, } \\
\text { neoplastic, toxic, or infectious } \\
\text { causes, RCVS, MMD }\end{array}$ & $\begin{array}{l}\text { moyamoya syndrome, intracranial } \\
\text { atherosclerosis, Sneddon syndrome, } \\
\text { Divry-van Bogaert syndrome, RCVS, PACNS }\end{array}$ \\
\hline
\end{tabular}

Abbreviations: CADASIL = cerebral autosomal dominant arteriopathy with subcortical infarcts and leukoencephalopathy; FMD = fibromuscular dysplasia; ICA = internal carotid artery; ICH = intracerebral hemorrhage; IS = ischemic stroke; SAH = subarachnoid hemorrhage; TCD = transcranial Doppler.

to separate these conditions, our patient's CSF pleocytosis was more consistent with PACNS. In one comparative analysis of the 2 conditions, conventional angiography was diagnostic in all cases of MMD, whereas PACNS often had false-negatives. ${ }^{8}$ In PACNS that affects medium to large vessels, angiography can often show areas of thinning and dilation with areas of significant stenosis, ${ }^{5}$ whereas MMD is characterized by occlusion of the distal ICAs with the presence of significant collateral networks. ${ }^{9}$

In reviewing the presentation of $\mathrm{MMD}$, it is important to note although it is a chronic disease, its presentation can be variable, ranging from an insidious course to a fulminant clinical decline. ${ }^{9}$ However, studies estimate that after direct revascularization therapy, the annual stroke rate is about $0.0 \%-1.6 \% .{ }^{10}$ In our patient's case, apoplexy may have induced cerebral vasoconstriction in vessels that were already maximally dilated, resulting in decreased tissue perfusion and ischemia. This case serves to highlight that in scenarios in which the clinical presentation does not conform to expectations, it is important to revisit the diagnosis and pursue additional testing, especially when the differential diagnosis is composed of diseases with markedly different treatment strategies.

\section{Author contributions}

Alvin S. Das: study concept and design, acquisition of data, manuscript drafting. David P. Lerner: study concept and design, acquisition of data, manuscript drafting. Xenos L. Mason: study concept and design, acquisition of data. Mohammad
A. Aziz-Sultan: study concept and design, acquisition of data. Henrikas Vaitkevicius: study concept and design, critical revision of manuscript. Steven K. Feske: study supervision, critical revision of manuscript. Saef Izzy: study concept and design, acquisition of data, critical revision of manuscript.

\section{Study funding}

No targeted funding reported.

\section{Disclosure}

The authors report no disclosures relevant to the manuscript. Go to Neurology.org/ $\mathrm{N}$ for full disclosures.

\section{References}

1. Gambaracci G, Rondoni V, Guercini G, Floridi P. Pituitary apoplexy complicated by vasospasm and bilateral cerebral infarction. BMJ Case Rep 2016;2016 bcr2016216186.

2. Salvarani C, Brown RD, Calamia KT, et al. Primary central nervous system vasculitis: analysis of 101 patients. Ann Neurol 2007;62:442-451.

3. Birnbaum J, Hellmann DB. Primary angiitis of the central nervous system. Arch Neurol 2009;66:704-709.

4. Dankbaar JW, Slooter AJ, Rinkel GJ. Schaaf IC. Effect of different components of triple- $\mathrm{H}$ therapy on cerebral perfusion in patients with aneurysmal subarachnoid haemorrhage: a systematic review. Crit Care 2010;14:R23.

5. Berlit P. Diagnosis and treatment of cerebral vasculitis. Ther Adv Neurol Disord 2010, 3:29-42.

6. Berlit P, Kraemer M. Cerebral vasculitis in adults: what are the steps in order to establish the diagnosis? Red flags and pitfalls. Clin Exp Immunol 2014;175:419-424.

7. Calabrese LH, Dodick DW, Schwedt TJ, Singhal AB. Narrative review: reversible cerebral vasoconstriction syndromes. Ann Intern Med 2007;146:34-44.

8. Kraemer M, Berlit P. Primary central nervous system vasculitis and moyamoya disease: similarities and differences. J Neurol 2010;257:816-819.

9. Scott RM, Smith ER. Moyamoya disease and moyamoya syndrome. N Engl J Med 2009;360:1226-1237.

10. Kim T, Oh CW, Bang JS, Kim JE, Cho WS. Moyamoya disease: treatment and outcomes. J Stroke 2016;18:21-30. 


\section{Neurology}

\section{Clinical Reasoning: Moyamoya disease masquerading as acute refractory cerebral vasospasm}

Alvin S. Das, David P. Lerner, Xenos L. Mason, et al.

Neurology 2018;91;e594-e598

DOI 10.1212/WNL.0000000000005952

This information is current as of August 6, 2018

Updated Information \& Services

References

Subspecialty Collections

Permissions \& Licensing

Reprints including high resolution figures, can be found at: http://n.neurology.org/content/91/6/e594.full

This article cites 10 articles, 1 of which you can access for free at: http://n.neurology.org/content/91/6/e594.full\#ref-list-1

This article, along with others on similar topics, appears in the following collection(s):

All Cerebrovascular disease/Stroke

http://n.neurology.org/cgi/collection/all_cerebrovascular_disease_strok

Critical care

http://n.neurology.org/cgi/collection/critical_care

Infarction

http://n.neurology.org/cgi/collection/infarction

Other cerebrovascular disease/ Stroke

http://n.neurology.org/cgi/collection/other_cerebrovascular_disease_s troke

Stroke in young adults

http://n.neurology.org/cgi/collection/stroke_in_young_adults

Information about reproducing this article in parts (figures,tables) or in its entirety can be found online at:

http://www.neurology.org/about/about_the_journal\#permissions

Information about ordering reprints can be found online:

http://n.neurology.org/subscribers/advertise

Neurology ${ }^{\circledR}$ is the official journal of the American Academy of Neurology. Published continuously since 1951, it is now a weekly with 48 issues per year. Copyright (O) 2018 American Academy of Neurology. All rights reserved. Print ISSN: 0028-3878. Online ISSN: 1526-632X.

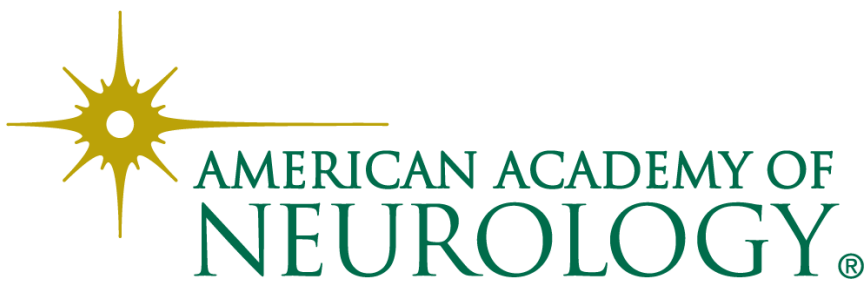

